\title{
Formulation of Ketorolac Tromethamine for Controlled Release in Gastrointestinal and Colonic Delivery System
}

\author{
Md. Amzad Hossain ${ }^{1}$, Swapon Kumar Shill' ${ }^{2}$, Shakhawat Hasan Khan ${ }^{2}$, S. M. \\ Moazzem Hossen ${ }^{3}$ and Mohammad Nasir Uddin ${ }^{2 *}$
}

\author{
1Department of Pharmacy, \\ University Science and \\ Technology Chittagong, \\ Bangladesh. \\ 2Department of Chemistry, \\ University of Chittagong, \\ Chittagong-4331, \\ Bangladesh. \\ 3Department of Pharmacy, \\ University of Chittagong, \\ Chittagong-4331, \\ Bangladesh.
}

Submitted: 08-02-2018

Revised: 20-03-2018

Accepted: $16-04-2018$

*Corresponding author

M. Nasir Uddin

*Corresponding author

Email: nasircu72@gmail.com

\begin{abstract}
A suitable matrix system of ketorolac tromethamine (KTR) formulation has been developed with the aim of increasing the contact time, achieving controlled release, reducing the frequency of administration, improving patient compliance. In this concern an enteric-coated KTR matrix tablet intended for specific delivery of drugs to the colon by combining the use of a time dependent core with a $\mathrm{pH}$-sensitive film coating. Eudragit L100, with a threshold $\mathrm{pH} 7$, was selected as coating material. New formulation is proved to be noble as to KTR delivery through both gastrointestinal and colonic system. New formulation is considered to reduce gastrointestinal side effects and achieve high local drug concentration at the afflicted site in the gastrointestine and colon.
\end{abstract}

Key words: Drug Formulation, Ketorolactromethamine, gastrointestinal and colonic delivery system, HPLC analysis

\section{INTRODUCTION}

The magnitude of these fluctuations due to the administration of drugs in conventional dosage forms depends on the rates of absorption, distribution and elimination and dosing intervals. Again though intravenous administration of drug provides the advantages like direct entry of drug into the systemic circulation, and control of circulating drug levels but this drug delivery has certain disadvantages, which would require hospitalization of the patients and close medical supervision of the medication (Joseph et al.1987). The novel drug delivery system includes transdermal drug delivery system, mucoadhesive drug delivery system, nasal drug delivery system, gastrointestinal, colonic drug delivery system etc.

Ketorolac tromethamine (KTR) (Figure 1), a potent nonnarcotic analgesic with moderate anti-inflammatory activity, has been investigated extensively for use in postoperative analgesia and has an excellent applicability in the emergency treatment of postoperative cancer pain and in the treatment of migraine pain (Andrade et al., 1994). As the biological half-life of KTR is 4-6 h frequent dosing is necessary to sustain the action of drug to alleviate pain in postoperative patients. It causes gastro intestinal complications including irritation, ulcer, bleeding and perforation when administered as the conventional formulation (Shankar and Mishra, 2003; Shyamala and Sanmathi, 2001). Although oral bioavailability of KTR was reported to be $90 \%$ with a very low first pass metabolism, its short biological half-life and many adverse effects, such as upper abdominal pain and gastrointestinal ulceration, restrict its oral use.<smiles>NC(CO)(CO)CO</smiles>

Figure 1. Structural formulae for ketorolac tromethamine 
Oral administration of different dosage forms has high patient acceptance due to greater flexibility in design of dosage form but the gastrointestinal tract presents several formidable barriers to drug delivery (Girish et al., 2006). Colon has a large amount of lymphoma tissue negligible brush boarder membrane activity and much less pancreatic enzymatic activity as compared with the small intestine. Therefore, in oral colon-specific drug delivery system facilitates direct absorption in to the blood (Chourasia, Jain, 2003) and this delivery by oral route has gained increased importance from last two decades to treat local diseases associated with colon (Vincent, 2002). The traditional approaches for colon targeting are prodrug formulation, $\mathrm{pH}$-sensitive drug delivery, time-dependent systems and microbial degradation methods to formulate different dosage forms (Vemula, 2009). With conventional tabletting facilities and less processing variables, formulation of matrix tablets is inexpensive method and easy to manufacture (Demiroz et al., 2004).

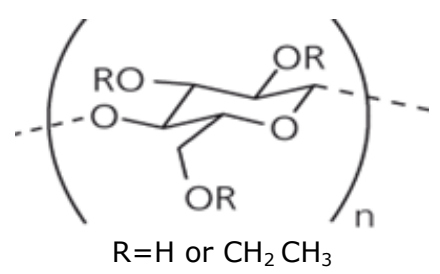

Figure 2. Ethyl cellulose, a synthetic retardant widely used as a release agent

Preparation of matrix tablets is simple method compared to other methods like tablets coated with different polymers and chemical conjugation of drug. Ethyl cellulose (Figure 2), a synthetic retardant, is widely used as an extended release agent in the pharmaceutical industry. Ethyl cellulose is an inert, hydrophobic polymer and is essentially tasteless, odorless, colorless, non-caloric, and physiologically inert. As solvent-based tablet and pellet coating, tablet binder, to prepare microcapsules and microspheres Ethyl cellulose has long been used. It is also used both as filmand matrix- forming material for sustainedrelease dosage forms. It shows good swelling and gel-forming properties and its controlled release mechanism is applied to formulate colon specific matrix tablets. Ethyl cellulose can be applied to prepare sustained release tablets by direct compression. Lower viscous grades of ethyl cellulose or a higher percentage of ethyl cellulose in the formulation can slow down the drug release rate. Furthermore, it has been seen that lower viscous grades produce harder tablets and a smaller particle size leads to a slower release rate. Membranes made of only Ethyl cellulose are water insoluble with good mechanical properties, but poor water permeability. These properties strongly decrease the release of an active substance. Sodium alginate, a hydrophilic biopolymer is used to increase the permeability of films. Combination of both swells and drug molecules begin to move out of the system by diffusion.

In fact the polymers used to achieve colon targeting should be able to withstand, unchanged, the lower $\mathrm{pH}$ values of stomach and small intestine and dissolve at the neutral or slightly alkaline $\mathrm{pH}$ of the terminal ileum (Chourasia, 2003). Keterolac tromethamine (KTR), a non-steroidal anti-inflammatory drug was efficient to treat inflammation and pain related to colon. The frequent intake of NSAIDS like KTR leads to gastric ulceration, bleeding and other gastric complications (Chopra et al., 2008). Hence the objective is to develop new KTR formulation for the delivery through both gastrointestinal and colonic system. That is to reduce gastrointestinal side effects and achieve high local drug concentration at the afflicted site in the gastrointestine and colon, optimal therapeutic effectiveness and good patient compliance.

\section{MATERIAL AND METHODS}

KTR was gift sample from Glaxosmithkline Labs, Chittagong, Bangladesh. $\mathrm{Na}$ alginate, $\mathrm{Mg}$ stearate, Xanthine gum, Guar gum etc. of analytical grade (purity > 95\%) were supplied by local agents of Aldrich Co. Ethyl cellulose (EC), actual viscosity 9.9 centipoises, was obtained from ICN Biomedicals, Inc. (Ohio, USA). Eudragit L 100 (purity $>95 \%$ ) was gift samples from Opsonin Pharmaceutical Ltd. Bangladesh. All other chemicals and solvents used were also of pharmaceutical grade. 
Table I. The compositions of the matrix tablets of proposed formulation

\begin{tabular}{lcccccc}
\hline Ingredient & F1 & F2 & F3 & F4 & F5 & F6 \\
\hline Ketorolac tormethamine & $10 \mathrm{mg}$ & $10 \mathrm{mg}$ & $10 \mathrm{mg}$ & $10 \mathrm{mg}$ & $10 \mathrm{mg}$ & $10 \mathrm{mg}$ \\
Xanthine gum & $10 \mathrm{mg}$ & 0 & 0 & 0 & $10 \mathrm{mg}$ & $5 \mathrm{mg}$ \\
Guar gum & 0 & $10 \mathrm{mg}$ & 0 & 0 & $10 \mathrm{mg}$ & $5 \mathrm{mg}$ \\
Ethyl cellulose & 0 & 0 & $10 \mathrm{mg}$ & 0 & $10 \mathrm{mg}$ & $5 \mathrm{mg}$ \\
Na alginate & 0 & 0 & 0 & $10 \mathrm{mg}$ & $10 \mathrm{mg}$ & $5 \mathrm{mg}$ \\
DCP & $178 \mathrm{mg}$ & $178 \mathrm{mg}$ & $178 \mathrm{mg}$ & $178 \mathrm{mg}$ & $148 \mathrm{mg}$ & $168 \mathrm{mg}$ \\
Mg stearate & $2 \mathrm{mg}$ & $2 \mathrm{mg}$ & $2 \mathrm{mg}$ & $2 \mathrm{mg}$ & $2 \mathrm{mg}$ & $2 \mathrm{mg}$ \\
Total weight & $200 \mathrm{mg}$ & $200 \mathrm{mg}$ & $200 \mathrm{mg}$ & $200 \mathrm{mg}$ & $200 \mathrm{mg}$ & $200 \mathrm{mg}$ \\
\hline
\end{tabular}

Table II. Composition of coating solution

\begin{tabular}{clc}
\hline Sr. No & Name of reagent & Amount used \\
\hline 1 & Eudragit L 100 & $5 \%$ \\
2 & Talc & $2 \%$ \\
3 & PEG 400 & $1 \%$ \\
4 & Ethanol & QS \\
\hline
\end{tabular}

\section{Powder characterization}

Before preparation of tablets, the powder mixtures of different formulations were evaluated for angle of repose, bulk density tapped density and compressibility index. The angle of repose $(\theta)$ was measured using fixed funnel method and it was calculated using the following formula:

$\theta=\frac{h}{r}$

Where, $b$ is height of the cone and $r$ is radius of the cone base. Angle of repose less than 30 shows the free flowing of the material.

The compressibility index or Carr's Index is a measure of the propensity of a powder to be compressed. Carr's Index is determined from the bulk and tapped densities. It is calculated using the following formula:

Carr's Index $=\left[\frac{[(\rho \mathrm{tap}-\rho \mathrm{b})}{\rho \operatorname{tap}} \times 100\right]$

Where, @b is bulk density and gtap is tapped density.

\section{Preparation of matrix tablets}

Wet granulation method was used to prepare the KTR matrix tablets. In this method, accurately weighed quantities of KTR, ethyl cellulose and excipients other than glidant and lubricant were passed through 60-mesh sieve and mixed in a poly bag for 5-10 min, then granules were prepared with the addition of sufficient amount of $5 \%$ poly vinyl pyrrolidine in alcohol as binding agent, dried and sieved to obtain uniform size granules. The obtained granules were lubricated with talc and magnesium stearate for another 5 min blending and the resultant mixture was compressed into tablets with $8 \mathrm{~mm}$ round flat punches using 16station rotary tabletting machine. The final weight of the tablet was adjusted to $200 \mathrm{mg}$. Batch size was limited to 100g. The compositions of the matrix tablets (Table I).

\section{Composition and preparation of coating solution}

The compositions of coating solution are given in following table. Eudragit L100 was dissolved in organic solvent $5 \% \mathrm{w} / \mathrm{v}$ (ethanol), and then it was stirred until the uniform mixture was formed. To this Talc $2 \%$ was added again it was stirred until uniform dispersion were formed. Then 1\% plasticizer was added and it was stirred until uniform mixture was formed. Coating is done by using a conventional coating pan. The coating parameters (Table II). 


\section{Preparation of enteric coated tablets}

The enteric coated tablets were prepared by using conventional coating pan. Coating solution was prepared by dissolving coating polymer in to the ethanol and uniform dispersion of coating solution was spray on the tablet bed under the following condition; spray air pressure $\mathrm{kg} / \mathrm{cm}^{2}$, inlet temperature outlet temperature rotating speed of pan $15 \mathrm{rpm}$. The coated tablets were dried for $10-15 \mathrm{~mm}$. in coating pan by inching. The amount of coating was done up to 8 to $10 \%$ per tablets. The tablets were coated at different levels from about 10 to $20 \% \mathrm{w} / \mathrm{w}$ of solid eudragit.

\section{Evaluation of physical parameters}

Physical properties like weight variation, hardness and friability were studied for the prepared tablets. 20 tablets of each formulation were weighed using an electronic weighing balance (AW 120, Shimadzu Corporation, Japan) for estimating weight variation. Monsanto tablet hardness tester was used for measuring the hardness of six tablets. Using Roche friabilator, friability was determined on ten tablets.

\section{Determination of drug content}

Drug content was determined by crushing ten tablets and $100 \mathrm{mg}$ of the powder was accurately weighed and transferred into a $100 \mathrm{~mL}$ volumetric flask. Initially about $50 \mathrm{~mL}$ of mobile phase was added to the volumetric flask and allowed to stand for 6-8h with intermittent shaking to ensure complete solubility of the drug. Then the volume was made up to $100 \mathrm{~mL}$ with mobile phase, filtered and analyzed for KTR content by the HPLC method (Uddin et al. 2014). The mobile phase mixture of $\mathrm{CH}_{3} \mathrm{OH}, \mathrm{CH}_{3} \mathrm{CN}$ and $0.02 \mathrm{M}$ $\mathrm{NaH}_{2} \mathrm{PO}_{4}$ by the composition of 50:10:40 $(v / v)$ was optimized at isocratic program. A flow-rate of $0.20 \mathrm{~mL} \mathrm{~min}^{-1}$ was chosen as a compromise analysis time. Reversed-phase Kinetex C18 (100 $\times 2.10 \mathrm{~mm}, 2.6 \mu \mathrm{m})$ column and $320 \mathrm{~nm}$ was selected for monitoring the drug using UV detector. Prior to the injection of the drug solution, the column was equilibrated for at least 30min with the mobile phase flowing through the system.

\section{In-vitro dissolution study}

In vitro drug release studies of KTR matrix tablets were carried out using USP XXIV Type I dissolution apparatus (Electro lab, TDT-08L) at a rotation speed of 50rpm and temperature of $37 \pm 0.5^{\circ} \mathrm{C}$. In order to simulate the gastrointestinal transit conditions, the tablets were subjected to different dissolution media. Initially, the drug release was carried out for $2 \mathrm{~h}$ in $0.1 \mathrm{~N} \mathrm{HCl}, 2 \mathrm{~h}$ in buffer $\mathrm{pH}$ 5.5 and finally in phosphate buffer $\mathrm{pH} 7.5$ up to $24 \mathrm{~h}$. At specific time intervals, $5 \mathrm{~mL}$ of the sample were withdrawn and replaced by an equal volume of fresh pre-warmed dissolution medium. The samples were filtered through $0.45 \mu \mathrm{m}$ membrane filter (Millipore, USA) and analyzed at $322 \mathrm{~nm}$.

\section{In-vitro release kinetics}

To explain the pattern and the release mechanism from the formulations, the data obtained from the in vitro dissolution studies was fitted to zero order, first order and Higuchi models (Wu et al., 2007). The mechanism of drug release from these formulations was determined using Koresmeyer-Peppas model (Valluru et al., 2008). The mathematical expression of Koresmeyer-Peppas equation is as follows

$\frac{M_{t}}{M_{a}}=k t^{n}$

In which, $M_{t} / M_{a}$ is the fractional amount of drug released at time $\mathrm{t}, \mathrm{k}$ is a kinetic rate constant, and $\mathrm{n}$ is the diffusional exponent that characterizes the mechanism of drug release. The values of the coefficient were calculated using linear regression analysis between $\log \mathrm{M}_{\mathrm{t}}$ $/ \mathrm{M}_{\alpha}$ and log t data obtained from drug release studies. The value of $\mathrm{n}$ was obtained as slope of the regression equation, and $\mathrm{K}$ was calculated as antilog of the intercept value (Asghar et al., 2009).

The $\mathrm{n}$ value is $<0.45$ suggests the Fickian release (diffusion controlled), for $\mathrm{n}$ is $>0.45$ and $<0.89$ it is non-Fickian release (diffusion and polymer relaxation), 0.89 for case II release (only relaxation and swelling), and for $>0.89$ it suggests super case II release (relaxation and erosion) for swellable systems. 
Table III. Pre-formulation study (average) for proposed formulation

\begin{tabular}{|c|c|c|c|c|c|}
\hline Sr.no. & Formulation & Bulk density & Tap density & Compressibility & Angle of repose $(\theta)$ \\
\hline 1 & F1 & $0.58 \pm 0.04$ & $0.67 \pm 0.05$ & $9.63 \pm 0.8$ & $26.89 \pm 0.4$ \\
\hline 2 & F2 & $0.62 \pm 0.4$ & $0.72 \pm 0.04$ & $11.35 \pm 0.3$ & $28.25 \pm 0.7$ \\
\hline 3 & F3 & $0.61 \pm 0.04$ & $0.71 \pm 0.04$ & $10.2 \pm 0.4$ & $29.74 \pm 0.4$ \\
\hline 4 & F4 & $0.65 \pm 0.04$ & $0.75 \pm 0.03$ & $9.29 \pm 0.1$ & $28.77 \pm 0.3$ \\
\hline 5 & F5 & $0.59 \pm 0.04$ & $0.61 \pm 0.04$ & $10.88 \pm 0.4$ & $29.62 \pm 0.7$ \\
\hline \multirow[t]{2}{*}{6} & F6 & $0.59 \pm 0.05$ & $0.79 \pm 0.04$ & $10.29 \pm 0.09$ & $31.15 \pm 0.06$ \\
\hline & average \pm SD & $0.60 \pm 0.02$ & $0.70 \pm 0.06$ & $10.27 \pm 0.76$ & $29.07 \pm 1.45$ \\
\hline
\end{tabular}

*All values represent mean \pm standard deviation, $n=10$

Table IV The physical properties of new formulation

\begin{tabular}{|c|c|c|c|c|c|c|}
\hline Sr. no & Formulation & $\begin{array}{l}\text { Weight } \\
\text { (mg) }\end{array}$ & $\begin{array}{c}\text { Thickness } \\
\text { (mm) }\end{array}$ & $\begin{array}{l}\text { Hardness } \\
\left(\mathrm{kg} / \mathrm{cm}^{2}\right)\end{array}$ & $\begin{array}{l}\text { Diameter } \\
\text { (mm) }\end{array}$ & $\begin{array}{c}\% \\
\text { Friability }\end{array}$ \\
\hline 1 & F1 & $203.7 \pm 3.12$ & $2.15 \pm 0.04$ & $5.78 \pm 0.1$ & $7.06 \pm 0.05$ & $0.065 \pm 0.0$ \\
\hline 2 & $\mathrm{~F} 2$ & $204.61 \pm 3.7$ & $2.007 \pm 0.01$ & $5.36 \pm 0.3$ & $7.06 \pm 0.11$ & $0.211 \pm 0.0$ \\
\hline 3 & F3 & $204.16 \pm 2.27$ & $2.022 \pm 0.01$ & $5.82 \pm 0.11$ & $7.12 \pm 0.40$ & $0.24 \pm 0.01$ \\
\hline 4 & F4 & $202.59 \pm 2.5$ & $2.033 \pm 0.01$ & $5.4 \pm 0.02$ & $7.8 \pm 0.01$ & $0.03 \pm 0.0$ \\
\hline 5 & F5 & $201.64 \pm 1.1$ & $2.11 \pm 0.2$ & $5.41 \pm 0.08$ & $7.14 \pm 0.04$ & $0.09 \pm 0.0$ \\
\hline \multirow[t]{2}{*}{6} & F6 & $201.98 \pm 2.21$ & $2.05 \pm 0.02$ & $5.4 \pm 0.05$ & $7.82 \pm 0.01$ & $0.04 \pm 0.04$ \\
\hline & average \pm SD & $203.11 \pm 1.2$ & $2.06 \pm 0.05$ & $5.52 \pm 0.21$ & $7.33 \pm 0.37$ & $0.12 \pm 0.9$ \\
\hline
\end{tabular}

$*$ All values represent mean \pm standard deviation, $\mathrm{n}=10$

For cylindrical systems like tablets, the $\mathrm{n}$ values of 0.45 and 0.89 represent pure diffusion or erosion controlled release, respectively (Mundargi et al. 2007).

\section{Drug-polymer interaction studies}

The possible interaction between KTR and ethyl cellulose was studied. The infrared spectra of KTR and optimized formulation (F4-F6) recorded within 400 to $4000 \mathrm{~cm}^{-1}$ on FTIR to detect the drug-excipient interactions. The IR spectra for the test samples were obtained using $\mathrm{KBr}$ disk method using an FTIR spectrometer (Model-883, Perkin Elmer FTIR, Perkin Elmer Inst. USA). The resultant spectra were compared for any possible changes in the peaks of the spectra. It is further confirmed by the peak purity of LC chromatogram.

Stability studies

To assess the drug and formulation stability, stability studies were done according to $\mathrm{ICH}$ and WHO guidelines. Optimized formulation F4 sealed in aluminum packaging coated inside with polyethylene, and various replicates were kept in the humidity chamber maintained at $25^{\circ} \mathrm{C}$ and $75 \% \mathrm{RH}$ for six months. Samples were collected after three and six months of storage and analyzed for the drug content and in vitro dissolution rate (Mathews, 1999).

\section{RESULTS AND DISCUSSION Powder characterization}

The powder mixtures of different formulations were evaluated for angle of repose, bulk density, tapped density, compressibility index and their values (Table III). The average apparent and tapped bulk density values of $0.60 \pm 0.02$ and $0.70 \pm 0.06$, respectively. The average value of angle of repose and \% Carr's index are $29.07 \pm 1.45$ and $10.27 \pm 0.76$, respectively.

\section{Evaluation of physical parameters}

The physical properties of formulation matrix tablets (Table IV). In weight variation test, the pharmacopoeial limit for the tablets of not more than $7.5 \%$ of the average weight and found to be $203.11 \pm 1.2 \mathrm{mg}$. 
Table V. Drug content uniformity results for proposed formulation

\begin{tabular}{lllll}
\hline S1. no. & $\begin{array}{l}\text { Batch } \\
\text { code }\end{array}$ & $\begin{array}{l}\text { Labeled amount of drug } \\
\text { in each tablet }(\mathbf{x})\end{array}$ & $\begin{array}{l}\text { Actual drug content }(\mathbf{m g}) \\
\text { in each tablet }(\mathbf{y})\end{array}$ & $\begin{array}{l}\text { \% drug content } \\
\mathbf{( y / x ) 1 0 0}\end{array}$ \\
\hline 1 & F1 & 10 & $10.37 \pm 0.52$ & $103.4 \pm 1.21$ \\
2 & F2 & 10 & $10.20 \pm 0.21$ & $102.1 \pm 1.64$ \\
3 & F3 & 10 & $10.17 \pm 0.09$ & $104.7 \pm 1.22$ \\
4 & F4 & 10 & $10.18 \pm 0.09$ & $103.00 \pm 1.81$ \\
5 & F5 & 10 & $11.20 \pm 0.26$ & $101.2 \pm 2.60$ \\
6 & F6 & 10 & $9.21 \pm 0.24$ & $98.00 \pm 1.41$ \\
& & Average \pm SD & $10.22 \pm 0.63$ & $104.23 \pm 4.15$ \\
\hline
\end{tabular}

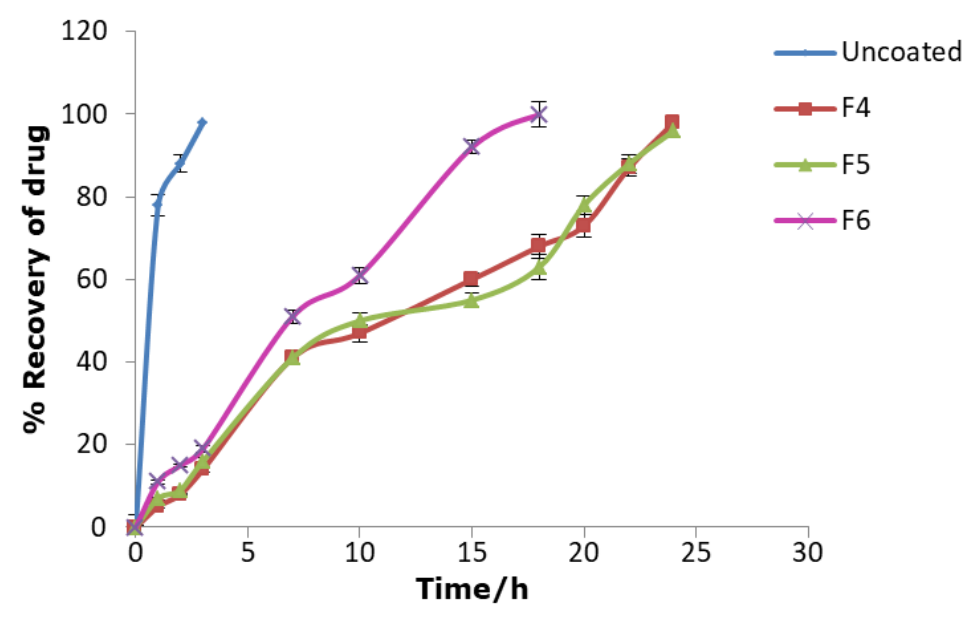

Figure 3. Comparison of Release profile of KTM from uncoated and Eudragit S100 coated tablets

The hardness of the tablets was found to be in the range of $5.52 \pm 0.21 \mathrm{~kg} / \mathrm{cm}^{2}$. Another measure of tablets strength is friability. Conventional compressed tablets that loss less than $1 \%$ of their weight are generally considered acceptable. The percentage friability for all formulations was below $1 \%$ i.e. $0.12 \pm 0.09 \%$, indicating that the friability is within the prescribed limits. The tablets were found to contain $104.23 \pm 4.15$ of the labeled amount indicating uniformity of drug content (Table V).

\section{Effect of cellulose amount on matrix integrity}

The cumulative mean percent of KTR released from matrix tablets containing varying amounts of ethyl cellulose was showed the suitable amount of polymer $(10 \mathrm{mg})$ to formulate a matrix tablet with good integrity and drug release properties.

\section{Effect of cellulose viscosity grade on matrix integrity}

Figure 3 showed the release profiles of KTR from the cellulose matrix tablets of different viscosity grades (F4-F6). The cumulative mean percent of KTR released from above formulations was found to vary from 55.78 to $63.77 \%$ after $5 \mathrm{~h}$ of testing in simulated gastric and intestinal fluids and the percent drug release was increased gradually after $5 \mathrm{~h}$ and it was found to be 89.34 to $92.23 \%$ in $24 \mathrm{~h}$.

\section{Effect of eudragit $L 100$ coating}

To study the effect of the coating level on drug release, in vitro dissolution studies in different $\mathrm{pH}$ (6.7-7.5) media were performed on F5 matrix tablets coated with different levels (10 to $20 \% \mathrm{w} / \mathrm{w}$ ) of Eudragit S100. The cumulative mean percent of KTR released from above F5 coated formulation was found to vary from $7.15 \pm 0.52$ after $5 \mathrm{~h}$ of testing in simulated 
Table VI. The $\mathrm{n}$ values calculated for different formulations according to zero order kinetics

\begin{tabular}{lllllll}
\hline Time / h & F 1 & F2 & F3 & F4 & F5 & F6 \\
\hline 1 & 1.01 & 1.02 & 0.98 & 1.02 & 1.00 & 1.01 \\
2 & 1.02 & 1.01 & 1.09 & 0.98 & 1.02 & 1.04 \\
3 & 1.09 & 1.06 & 1.05 & 1.06 & 1.84 & 1.01 \\
4 & 1.04 & 1.00 & 1.06 & 1.00 & 1.66 & 1.03 \\
5 & 1.04 & 1.01 & 1.05 & 1.04 & 1.63 & 1.05 \\
6 & 1.07 & 1.00 & 1.05 & 1.01 & 1.62 & 1.03 \\
7 & 1.05 & 1.00 & 1.02 & 1.09 & 1.59 & 1.04 \\
8 & 1.00 & 1.05 & 1.01 & 1.08 & 1.56 & 1.04 \\
9 & 1.04 & 1.09 & 1.06 & 1.04 & 1.53 & 1.01 \\
10 & 1.00 & 1.01 & 1.06 & 1.03 & 1.50 & 1.03 \\
11 & 1.09 & 1.05 & 1.01 & 1.09 & 1.48 & 1.03 \\
12 & 1.07 & 1.00 & 1.06 & 1.08 & 1.46 & 1.03 \\
13 & 1.08 & 1.06 & 1.05 & 1.05 & 1.46 & 1.02 \\
14 & 1.04 & 1.01 & 1.06 & 1.02 & 1.45 & 1.04 \\
15 & & & & 1.00 & 1.45 & 1.08 \\
16 & & & & 1.05 & 1.42 & 1.03 \\
17 & & & & 1.02 & 1.40 & 0.97 \\
18 & & & & 1.02 & 1.37 & 0.98 \\
19 & & & & 1.01 & 1.30 & \\
20 & & & & 1.07 & 1.22 & \\
21 & & & & 1.08 & 1.19 & \\
22 & & & & 1.03 & 1.12 & \\
23 & & & & & 1.02 & \\
24 & & & & & 0.91 &. \\
\hline
\end{tabular}

gastric and intestinal fluids and the percent drug release was increased gradually after $5 \mathrm{~h}$ and it was found to be complete drug release $(95.87 \pm 0.62 \%)$ in $24 \mathrm{~h}$.

\section{In-vitro release kinetics}

The values of $\mathrm{k}$, and $\mathrm{r}^{2}$ (correlation coefficient of the regression analysis) of zero order, first order and Higuchi models of designed formulations (Table VI). The n values calculated for different formulations were found in the range of 0.89-1.02.

\section{Drug-polymer interaction studies}

The FTIR spectrum of pure KTR and F1-F6 tablets exhibits a peak at $3487 \mathrm{~cm}^{-1}$ is due to the $\mathrm{N}-\mathrm{H}$ and $\mathrm{NH}_{2}$ stretching and peaks at $1460-1469 \mathrm{~cm}^{-1}, 1482-1495 \mathrm{~cm}^{-1}$ is due to $\mathrm{C}=\mathrm{C}$ aromatic and aliphatic stretching, peak at 1371$1411 \mathrm{~cm}^{-1}$ is due to $-\mathrm{C}-\mathrm{N}$ vibrations, peak at $1045-1060 \mathrm{~cm}^{-1}$ is due to $-\mathrm{OH}$ bending confirms presence of alcoholic group, peaks at $760-800 \mathrm{~cm}^{-1}$ confirms the $\mathrm{C}-\mathrm{H}$ bending (aromatic) thus, confirms the structure of drug KTR. FTIR of physical mixture showed that there is no interaction between drug and the polymers employed in formulation. FTIR spectra of formulation F5 is given (Figure 4).

The Differential scanning calorimetry (DSC) for trace of drug showed a sharp endothermic peak at $169.48^{\circ} \mathrm{C}$, its melting point. The physical mixture of drug and blank microspheres showed the same thermal behavior $168.96^{\circ} \mathrm{C}$ as the individual component, indicating that there was no interaction between the drug and the polymer in the solid state. The absence of endothermic peak of the drug at $169.48^{\circ} \mathrm{C}{ }^{\circ} \mathrm{C}$ in the DSC of the drug loaded microspheres suggests that the drug existed in an amorphous or disordered crystalline phase as a molecular dispersion in polymeric matrix. 


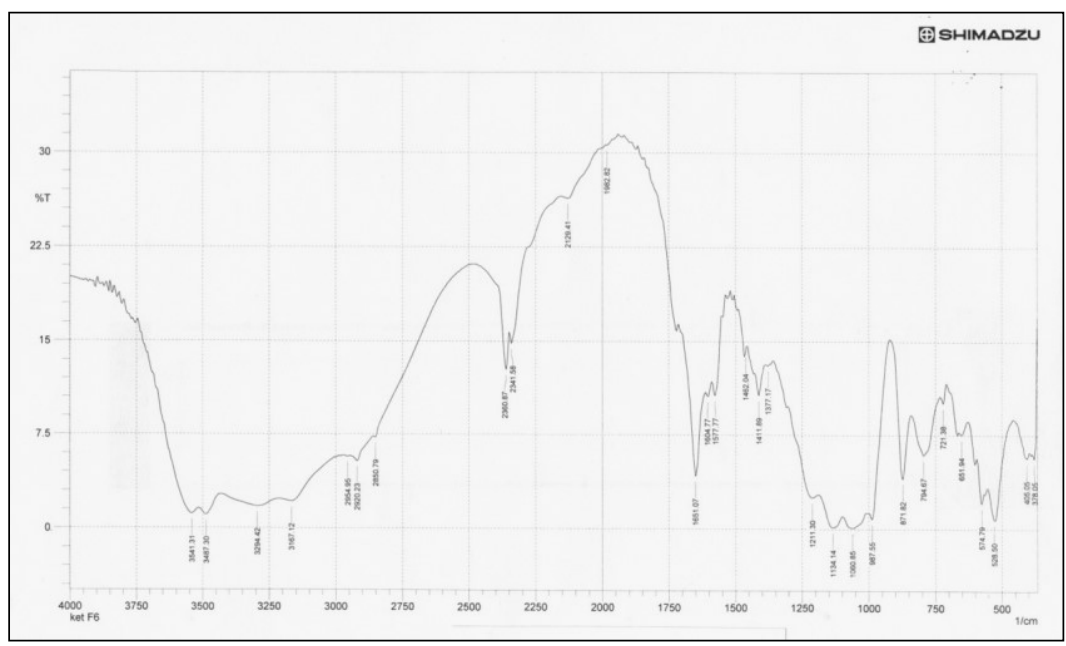

Figure 4. FTIR spectra of formulation F5 of KTR

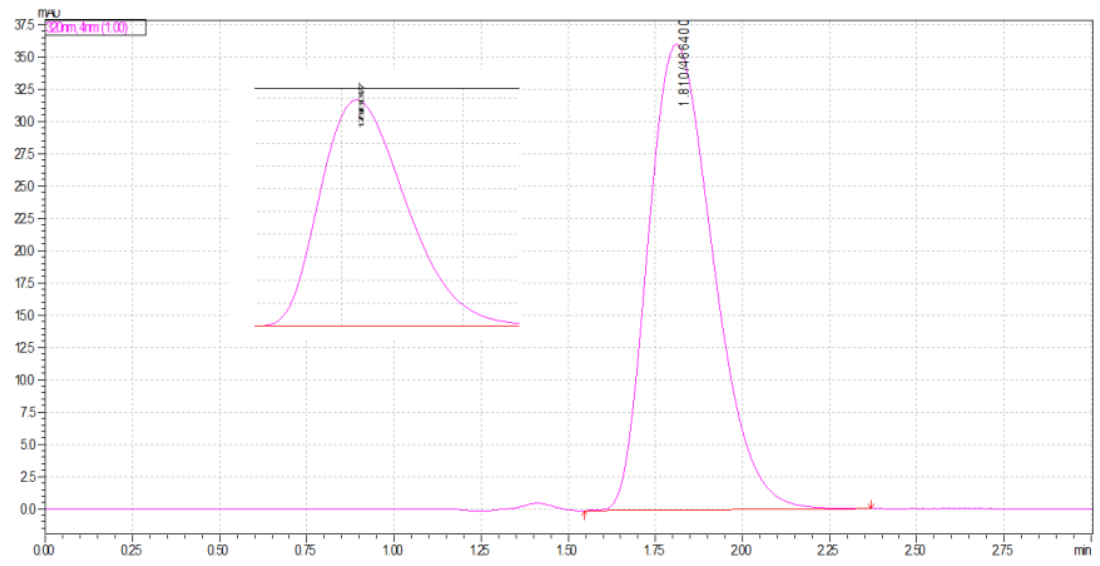

Figure 5. Typical UPLC chromatogram of the examined drug $\left(4 \mu \mathrm{gmL}^{-1}\right)$ in F5 formulation. Peaks: $1.78 \mathrm{~min}(\mathrm{KTR})$

LC Chrmatogram (Figure 5) shows that drug was identified free of interference from potential impurities and degradation products by the absence of any peak in the same retention times. There was no interference at retention time of Ketorolac due to back ground control sample. Retention time of KTR in all proposed formulation was found in $1.77 \pm 0.03 \mathrm{~min}$ at the RSD value of $1.78 \%$.

\section{Stability studies}

In view of the potential utility of the formulation, stability studies were carried out at $25^{\circ} \mathrm{C}$ for six months to assess their stability. After storage of three months, the formulation was subjected to a drug assay and in vitro dissolution studies (Figure 6).

The angle of repose and \% Carr's index were measured to determine the flow properties of powder mixtures of formulations and the results of angle of repose $(<30)$ and compressibility index $(<12)$ indicates fair to passable flow properties of the powder mixture (Staniforth and Aulton, 2007). In weight variation test, the pharmacopoeial limit for the tablets of not more than $7.5 \%$ of the average weight. The average percentage deviation of all tablet formulations was found to be within the above mentioned limit and hence all formulations passed the uniformity of weight as per official requirements. 


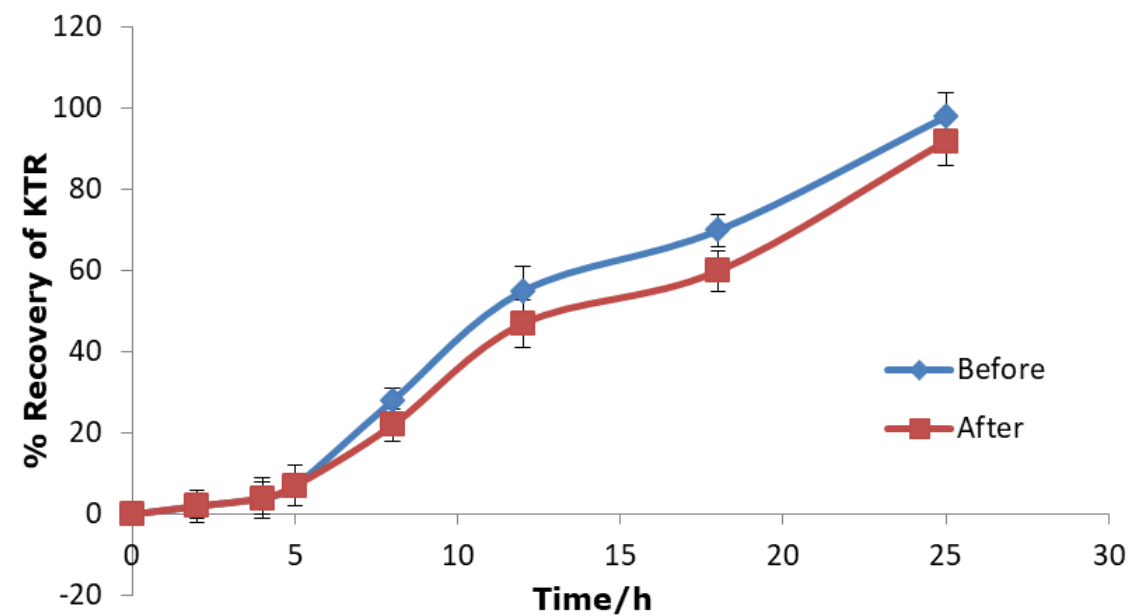

Figure 6. In vitro release study of KTR for the formulation F5 before (blue) and after (red) three months storage

Table VII. Estimation of ketorolac tromethamine in new formulation by validated new UPLC method

\begin{tabular}{|c|c|c|c|c|c|c|}
\hline Name & Conc. $\mu \mathrm{g} \mathrm{mL}^{-1}$ & Calcul. $\mu \mathrm{g} \mathrm{mL}^{-1}$ & $\% \mathbf{R}$ & Average $\% \mathrm{R}$ & Amount mg & $\%$ RSD \\
\hline \multirow[t]{3}{*}{ F1 } & 1 & 0.95 & 95.33 & & & 0.23 \\
\hline & 2 & 1.79 & 89.44 & 93.32 & 9.33 & 0.50 \\
\hline & 4 & 3.81 & 95.18 & & & 0.14 \\
\hline \multirow[t]{3}{*}{ F2 } & 1 & 1.05 & 105.19 & & & 0.88 \\
\hline & 2 & 2.13 & 106.57 & 105.512 & 12.4 & 1.93 \\
\hline & 4 & 4.19 & 104.79 & & & 1.57 \\
\hline \multirow[t]{3}{*}{ F3 } & 1 & 0.92 & 91.70 & & & 0.35 \\
\hline & 2 & 1.89 & 94.63 & 92.50 & 8.86 & 0.10 \\
\hline & 4 & 3.65 & 91.17 & & & 0.56 \\
\hline \multirow[t]{3}{*}{ F4 } & 1 & 1.09 & 109.34 & & & 0.59 \\
\hline & 2 & 2.18 & 109.16 & 109.41 & 10.95 & 0.17 \\
\hline & 4 & 4.39 & 109.72 & & & 2.58 \\
\hline \multirow[t]{3}{*}{ F5 } & 1 & 1.09 & 109.34 & & & 5.00 \\
\hline & 2 & 2.16 & 108.12 & 109.10 & 13.88 & 2.63 \\
\hline & 4 & 4.39 & 109.85 & & & 1.30 \\
\hline \multirow[t]{3}{*}{ F6 } & 1 & 1.09 & 108.82 & & & 0.50 \\
\hline & 2 & 2.09 & 104.49 & 105.56 & 10.55 & 0.29 \\
\hline & 4 & 4.13 & 103.36 & & & 0.45 \\
\hline
\end{tabular}

The hardness and friability are measured for tablets strength and integrity. All tablet formulations were uniform in hardness, friability and drug content uniformity.

To optimize the polymer content different formulations were prepared and evaluated for drug release using the ethyl cellulose. From the dissolution studies, the formulation containing $150 \mathrm{mg}$ of cellulose showed good drug release pattern in a controlled manner for $24 \mathrm{~h}$ with good physical properties and matrix integrity. Dissolution study of F1-F6 shows the effect of different viscosity grades of cellulose on release profiles of KTR from the cellulose matrix tablets. Formulations with cellulose of high viscosity 
formed swollen gel matrix with substantial integrity and the drug release was in a controlled manner which could be due to the better control of water and drug diffusion. In comparison with low viscosity grades of ethyl cellulose, the tablet lacks strength and was eroded quickly after swelling. Investigation showed almost $90 \%$ drug F1-F3 released in stomach and small intestine that doesn't comply with project aim. Present investigation showed 55\% drug release in the initial lag period and followed by controlled release for $24 \mathrm{~h}$, which is the normal residence time of solid dosage form in the colon (Krishnaiah et al., 1998). ${ }^{18}$ Formula F4-F5 showed the $55.78 \pm 0.75 \%$ drug release in the initial lag period (5h) followed by $36.24 \%$ (observed value - initial released drug; 92.02-55.78\%) drug release for $24 \mathrm{~h}$ in a controlled manner. This indicates that a minimal amount of the drug $(<50 \%)$ is released in the physiological environment of stomach and small intestine and remaining drug release $(<50 \%)$ was observed in colonic region. Thus the formulation F4-F5 were considered better among other formulations to produce colon and gastrointestinal specific drug delivery of KTR and it is further improved by Eudragit L100 polymeric coating. The drug delivery systems targeted to the stomach and small intestine should reduce the drug from being released in the physiological environment of colon (Vyas and Roop, 2006).

Eudragit L 100, a methacrylate copolymer, was selected as the enteric coated polymer. It is stable in acidic $\mathrm{pH}$ and dissolves at $\mathrm{pH}$ 7.5, considered as a suitable coating material for colonic drug delivery, by retarding the drug release at lower gastric and small intestine $\mathrm{pH}$ values. The lowest coating level to obtain a lag time (5h) was found at $20 \% \mathrm{w} / \mathrm{w}$ of polymeric coat (F6) to achieve gastrointestinal and colon specific drug release.

After storage of three months, the formulation was subjected to a drug assay and in vitro dissolution studies. Results show no significant degradation due to polymeric interaction happened. From the drug release kinetics studies, high correlation coefficient values for zero order than first order indicating that the drug release from matrix tablets followed zero order profile ensured the release of drug from matrix tablets followed diffusion mechanism. The ' $n$ ' values calculated for different formulations indicating a supercase-II transport.

From the IR spectral analysis all the principal peaks observed in pure drug were present in the IR spectra of the optimized formulation (F4-F6) and no additional peaks were observed with physical mixtures, which could be due to the presence of polymers. These results suggest that there is no interaction between the drug and polymers used in the present study. This results are also confirmed by the identifying the drug in LC chromatogram having free of interferences. Ketorolac tromethamine in new formulations has been estimated by validated new UPLC method. Percentage recovery (Table VII) is ranged from 92.49-109.4 with very excellent RSD of $0.14-5.08 \%$. This indicates that no interference occurred due to drug excipients. But in accordance to pre- and post-formulation investigation, formulation F4 and F5 are supposed to be acceptable having property of gastrointestinal, colonic drug delivery system. After storage of three months and six months, the formulation was subjected to a drug assay and in vitro dissolution studies and the data showed that there was no significant change in formulation in the sense of drug content and dissolution behavior.

\section{CONCLUSION}

The physical properties like weight variation, thickness, hardness and friability of all formulations were comply with pharmacopoeia standards, so all the tablets were to be acceptable with physical characteristics. Dissolution study of F1-F6 formulations shows the effect of different viscosity grades of cellulose on release profiles of KTR from the cellulose matrix tablets. Formulations F4-F5 were considered to be better among other formulations to produce KTR delivery through both gastrointestinal and colon systems simultaneously and it is further improved by Eudragit L100 polymeric coating. From the IR spectral and UPLC analysis indicate that no interference occurred due to drug excipients. 


\section{ACKNOWLEDGEMENTS}

Author thanks to University of Chittagong for supporting this study.

\section{REFERENCES}

Andrade JR., Maslanka M, Maneatis, T., Bynum L., Burchomore M. 1994. The use of ketorolac tromethamine in the management of post operative pain. Orthopedics, v. 17, p. 157-166.

Asghar LF., Chure CB.; Chandran S. 2009. Colon specific delivery of indomethacin: effect of incorporating ph sensitive polymers in xanthan gum matrix bases. AAPS Pharm Sci Tech., v. 10(2), p. 418429.

aShyamala B., Sanmathi BS. 2001. Polylactic acid) microspheres of ketorolac tromethamine for parenteral controlled drug delivery system. Indian J Pharm Sci., v. 63 , p. 538-540.

bShyamala B., Sanmathi BS. 2001. Innfluence of manufacturing parameters and the release profile of Ketorolac tromethamine from poly (Lactide-coglycolide) microspheres. Indian Drugs, v. 38, p. 383-385.

Chopra D., Sinha VR., Singh M. 2008. Thermal and isothermal methods in development of sustained release dosage forms of ketorolac tromethamine. E-J Chem., v. 5(2), p. 316-322.

Chourasia MK., Jain SK. 2003. Pharmaceutical approaches to colon targeted drug delivery systems. I Pharm Pharmaceut Sci., v. 6(1), p. 33-66.

Demiroz FT., Acarturk F., Takka S. Boyunaga OK. 2004. In-vitro and In-vivo Evaluation of Mesalazine-Guar Gum Matrix Tablets for Colonic Drug Delivery. J Drug Targ, v. 12(2), p. 105112.

Girish NP., Gayatri CP., Ritesh BP. 2006. Oral colon-specific drug delivery: an overview. Drug Delivery Tech., v. 6(7), p. 62-71.

Krishnaiah YSR., Satyanarayana S., Ramaprasad YV., Narasimharao S. 1998. Evaluation of guar gum as a compression coat for drug targeting to colon. Int J Pharm., v. 171, p. 137-146.
Mathews BR. 1999. Regulatory aspects of stability testing in Europe. Drug Dev Ind Pharm., v. 25, p. 831-856.

Mundargi RC., Patil SA. Agnihotri SA.; Aminabhavi, T.M. 2007. Development of polysaccharide-based colon targeted drug delivery systems for the treatment of amoebiasis. Drug Dev Ind Pharm., v. 33, p. 255-264.

Robinson JR., Lee VH. 1987. "Transdermal Therapeutic Systems" Charpter-12. in “" Control drug delivery," 2nd edition V 29, p 523-531.

Shankar C., Mishra M. 2003. Development and in-vitro evaluation of gelatin A microspheres of ketorolac tromethamine for intranasal administration. Acta Pharm., v. 53, p. 101-110.

Staniforth JN., Aulton ME. Powder flow. In Aulton ME. (Ed.) 2007. Aulton's Pharmaceutics-The Design and Manufacture of Medicines. Churchill Livingstone: Elsevier, Inc. p. 168-179.

Uddin MN, Das S., Khan S. H. Shill SK.; Bhuiyan HR., Karim R. 2014. A novel validated UPLC method for the estimation of ketorolac tromethamine in pharmaceutical formulation. Research v. 1, p. 1237.

Valluru R., Siddaramaiah T., Pramod M. 2008. Influence of natural polymer coating on novel colon targeting drug delivery system. J Mater Sci., v. 19, p. 2131-2136.

Vemula SK., Veerareddy P,R. 2009. Different approaches to design and evaluation of colon specific drug delivery systems. Int $J$ Pharm Tech., v. 1(1), p. 1-35.

Vincent HL., Suman KM. 2002. Drug deliveryoral colon-specific. In J. Swarbick and C. J. Boylan. (Ed.) Encyclopedia of Pharm Tech. New York: Marcel Dekker, Inc. p. 871885.

Vyas SP., Roop KK. 2006. Controlled drug delivery concepts and advances. 1st ed. Vallabh Prakashan Publishers, Delhi p. 218-256.

Wu B., Shun N., Wei X., Lu Y., Wu W. 2007. Biphasic release of indomethacin from $\mathrm{HPMC} /$ pectin/calcium matrix tablet: I. Characterization and mechanistic study. Eur J Pharm Biopharm., v. 67, p. 707-714 